\title{
Optimization setting of steel-smelting industry in the issue of alloy steels
}

\author{
I.U. Rakhmonov ${ }^{1,2^{*}}, N . N$. Niyozov $^{1}$ \\ ${ }^{1}$ Tashkent State Technical University named after Islam Karimov, 100095, Uzbekistan, Tashkent, University St. 2 A. \\ ${ }^{2}$ Karakalpak State University, 230100, Uzbekistan, Nukus, Ch. Abdirov St.1.
}

\begin{abstract}
It is very difficult to find any area of the state economy where metals and, in particular, steel are not required. The range of varieties has become enormous, and accordingly, the task of saving energy, fuel and resources for its manufacture becomes extremely urgent. Below in this context, we consider the procedures for the production of alloy steels, when each alloying additive has its own individual price, and the steel scheme is a narrowly specialized purpose.
\end{abstract}

The metallurgical industry consumes up to $7 \%$ of the total industrial electricity consumption of the Republic of Uzbekistan. At the same time, about $20 \%$ of the total energy consumption is spent on the production of steel and rolled products, and about $50 \%$ of the total energy consumption of resources in the industry is spent on the production of pig iron. The costs of providing energy resources account for a significant share of the cost of production, while improving the quality indicators and consumer properties of products, reducing its cost are the most important priorities for the activities of metallurgical enterprises [1].

At the same time, an increase in the quality indicators of products can be ensured only due to the additional consumption of energy resources by the corresponding new units without increasing the volume of production, which leads to an increase in its energy intensity. And at the same time, the specific energy intensity of products remains indicators of the efficiency of energy use at enterprises and refers to the main indicators of their performance. Reducing the energy intensity of products and financial costs, providing energy resources (which often does not coincide) is one of the foundations for the survival of enterprises, since it largely determines their competitiveness [2].

Alloy steels in the infrastructure of the state economy have an extremely wide range of applications. Special steel is required for the manufacture of firearms barrels, only slightly less "stringent" requirements are imposed on steel grades used for the manufacture of working elements of metal-cutting machines and other mechanisms of high accuracy and strength.

Parts and elements manufactured at a non"precision" level for machine tools were used on "consumer goods": cars, tractors, vehicles, etc. On a statewide scale, the shares of "demand" for various types of steel can be obtained from an analysis of the reporting of their use in previous years, as well as taking into account trends in the accelerated development of certain areas [3-4].

Of course, the "quota" of state power for the manufacture of firearms is legally defined and the composition of the steel production related to this part is strictly regulated, in no way connected with the production that allows optimization. That is what we will deal with below.

Imagine the income of steelmaking in the form of the Lagrange function [2];

$$
L=\sum_{i=1}^{n} C_{i}\left(b_{i}\right) T_{i}+\lambda W
$$

where the $T_{i}$ tariff per ton of steel with the $i$-th alloying additive, and the relationship of income with the corresponding production resources $b_{i}$ is expressed by the dependence $C_{i}\left(b_{i}\right) . \lambda$-indefinite Lagrange multiplier; $W$-auxiliary Lagrange function.

Since the payment for the consumed electricity at the proposed tariffs is determined by the financial condition of the state and therefore is quite stable (close to constant), the consumer will strive to provide a predetermined volume of production of finished goods with minimal own costs $(L \rightarrow \min )$ and, accordingly, with maximum profit. Achieving a minimum of costs is possible with the help of resource $b_{i}$ manipulation, known in economic theory [2].

By sequentially manipulating the tariff, the manufacturer provides a predetermined (demanded) volume of production of finished products with minimal resource costs. In [1], it was proved that in the optimum region of function (1), denoted by $L[C(b)]$, the derivative of (1) with respect to the resource corresponds to an indefinite Lagrange multiplier

Corresponding author: ilider1987@yandex.com 


$$
\lambda_{i}=\partial L\left[C\left(b_{i}\right)\right] / \partial b_{i}
$$

and is a marginal change in the optimal value of the objective function when changing the resource $b_{i}$. In [1], it is proposed to call $\lambda_{i}$ an estimate of the $i$-th resource.

Consider the auxiliary Lagrange function of the Wexpression (1). As applied to the problem of finding the minimum of functions, $\mathrm{W}$ can be a limiting balance between the resources used (fully) and their limiting values, i.e.

$$
W=B_{1 a d d}+B_{2 a d d}+\ldots+B_{\text {nadd }}-B_{1}-B_{2}-\ldots-B_{n}=0
$$

Taking into account (3), we find the conditions for achieving the minimum of expression (1). We find the partial derivatives with respect to resources and equate them to zero:

$$
\begin{aligned}
& \partial L / \partial b_{1}=\left[\partial C_{1}\left(b_{1}\right) / \partial b_{1}\right]\left(T_{1}-\lambda\right)=0 ; \\
& \partial L / \partial b_{2}=\left[\partial C_{2}\left(b_{2}\right) / \partial b_{2}\right]\left(T_{2}-\lambda\right)=0 ; \\
& \partial L / \partial b_{t}=\left[\partial C_{t}\left(b_{t}\right) / \partial b_{t}\right]\left(T_{t}-\lambda\right)=0 .
\end{aligned}
$$

From (4) we determine the conditions for obtaining a minimum:

or

$$
\begin{aligned}
\lambda & =\left[\partial C_{1}\left(b_{1}\right) \partial b_{1}\right] T_{1} /=\left[\partial C_{2}\left(b_{2}\right) / \partial b_{2}\right] T_{2}=\ldots \\
\ldots & =\left[\partial C_{t}\left(b_{t}\right) / \partial b_{t}\right] T_{t}
\end{aligned}
$$

$$
\lambda=\left[\partial C_{i}\left(b_{i}\right) / \partial b_{i}\right] T_{i}=\text { const }
$$

those. the minimum costs for the production of finished products by the enterprise of a given quantity will take place when the growth rates of income are equal for all resources used (or for all types of tariffs associated with them). It also means the equality of all "marginal workshops".

Consider the optimization problem that is solved by all electric consumers, while realizing that they should be as busy as possible, and electric consumers of steelmaking tend to produce the maximum amount of finished products necessary for the proposed tariffs [8].

We compose maximize the Lagrange function for different layers of consumers:

$$
L^{\prime}=\sum_{i=1}^{n} C_{i}\left(T_{i}\right) T_{i}^{*}+\lambda^{\prime} W^{\prime} \Rightarrow \max
$$

where $\sum C_{i}\left(T_{i}\right) T_{i}^{*}$ - payments for consumed electricity, steelmaking as a result of market balancing between supply and demand (optimized part).

The relationship between demand and current tariffs $T_{i}$ is characterized by the dependence $C_{i}\left(T_{i}\right) ; T_{i}$ - tariff as a constant proposed to electric consumers (each in its own time interval), to which the electric consumer answers with demand depending on its capabilities; $\lambda^{\prime}$ an indefinite factor; $\mathrm{W}^{\prime}$ - is the auxiliary function of Lagrange, for which it is advisable to use the maximum balanced correspondence between the tariffs $\mathrm{Ti}$ offered by energy supply companies and the tariffs $T_{i}{ }^{*}$ "demanded" by consumers [5-6].

In this way,

$$
W=T_{1}^{*}+T_{2}^{*}+\ldots T_{n}^{*}-T_{1}-T_{2}-\ldots-T_{n}=0
$$

It should be noted that the tariffs "demanded" by $\mathrm{T}_{\mathrm{i}}^{*}$ electric consumers are constants for a given period of society development, since they are characterized by the general level of production and consumption of the main and auxiliary production of steelmaking.

In view of (7), we determine the conditions for attaining the maximum of the Lagrange function (6). We take the partial derivatives of this function at the regulated tariffs $T_{i}$ and equate them to zero:

$$
\begin{aligned}
& \partial L^{\prime} / \partial T_{1}=\left[\partial C_{1}\left(T_{1}\right) / \partial T_{1}\right]\left(T_{1}^{*}-\lambda^{\prime}\right)=0 ; \\
& \partial L^{\prime} / T_{2}=\left[\partial C_{2}\left(T_{2}\right) / \partial T_{2}\right]\left(T_{2}^{*}-\lambda^{\prime}\right)=0 ; \\
& \partial L^{\prime} / \partial T_{t}=\left[\partial C_{t}\left(T_{t}\right) / \partial T_{t}\right]\left(T_{t}^{*}-\lambda^{\prime}\right)=0 .
\end{aligned}
$$

Find the undetermined Lagrange multiplier $\lambda^{\prime}$ from system (8):

$$
\begin{aligned}
& \lambda=\left[\partial C_{1}\left(T_{1}\right) \partial T_{1}\right] T_{1}^{*}=\left[\partial C_{2}\left(T_{2}\right) / \partial T_{2}\right] T_{2}^{*}=\ldots \\
& \ldots=\left[\partial C_{t}\left(T_{t}\right) / \partial T_{t}\right] T_{t}^{*} \\
& \text { or } \quad \lambda=\left[\partial C_{i}\left(T_{i}\right) / \partial T_{i}\right] T_{i}^{*}=\text { const }
\end{aligned}
$$

Condition (9) allows us to conclude that from the position of electric consumers in the steelmaking shop, the maximization of electricity consumption takes place with a set of tariffs that ensures equality of the increment rates of income of the main and auxiliary production for all types of tariffs. This indicates the "optimality" of the set of tariffs for electricity consumption and the "perception" of this set by all categories of consumers [7-8].

Consider the indefinite Lagrange multipliers $\lambda$ and $\lambda$ ' in functions optimized by (1) and (6). If the coefficient $\lambda$ is a factor balancing the distribution of resources, then the coefficient $\lambda^{\prime}$ is a factor balancing the distribution of tariffs for services. These coefficients are called dual variables (1). We accept the assumption:

$$
\lambda^{\prime}=k \lambda
$$

where $k$ is a linear coefficient that establishes for a balanced case the proportionality between electricity tariffs and the cost of energy used to produce finished products.

Using expressions (5), (9) and (10), we obtain $\left[\partial C_{i}\left(b_{i}\right) / \partial b_{i}\right] T_{i}=k\left[\partial C_{i}\left(T_{i}\right) / \partial C_{i}\left(T_{i}\right) / \partial T_{i}\right] T_{i}^{*}$

If in the process of market balancing of interests all proposed electricity tariffs turn out to be in demand $(\mathrm{T}=$ T), then expression (11) is simplified:

$$
\partial C_{i}\left(b_{i}\right) / \partial b_{i}=k\left[\partial C_{i}\left(T_{i}\right) / \partial T_{i}\right]
$$

What can be interpreted as a proportional change in the speed of demand for services depending on the energy consumed [9-10].

Returning to the issue of equality of income of enterprises of primary and secondary production, i.e. $\mathrm{L}=$ L', we summarize the findings:

$$
\min _{b_{i} \geq 0} L\left[\partial C_{i}\left(b_{i}\right), T_{i}=\max _{C} L^{\prime}\left[C_{i}\left(T_{i}\right), T_{i}^{*}\right]\right.
$$

The presence of double equality indicates an economically competitive equilibrium at some "Saddle" point. Finding a set of tariffs that meet condition (13) is 
considered a mathematical solution to the dual problem with Kuhn-Tucker conditions (1).

\section{Conclusion}

The set of tariffs defined in the article for electric smelters of steelmaking is optimal. Satisfaction of consumer demand, in turn, becomes the best incentive for social development in a competitive market in society as a whole.

For steelmaking, the task of increasing revenues and profitability of the main and auxiliary production translates into the strategic task of minimizing costs, which implies a consistent transition from the cheapest to the more expensive resources.

\section{References}

1. B.Kudrin, Electrician, 9, 35-45 (2003).

2. B.Kudrin, Ind. Ener., 6, 22-25 (2006).

3. V.Klyunya, FET, 238 (2006).

4. L.Koptsev, A.Koptsev, Ind. Ener., 1, 18-23 (2011).

5. A.Grinev, Ind. Ener., 3, 19-22 (2012).

6. L.Kazarinova, T.Barbasova, O.Kolesnikova, A.Zakharova, CTME, 14, 5-11 (2014).

7. M.Bazaar, K.Shetty, NPTA, 583 (1982).

8. F. Hoshimov, I.Rahmonov, JESR, 11-12, 56-59 (2014).

9. F.Hoshimov, .Rahmonov, AJTNS, 3-4, 52-55 (2015).

10. I.Rakhmonov, IJARSET, 6, 8183-8185 (2019). 